\title{
Public Housing Allocation Model in the Guangdong-Hong Kong-Macao Greater Bay Area under Clustering Algorithm
}

\author{
Lei Zhang $\mathbb{D}^{1,2}$ and Xueqing $\mathrm{Hu}^{3}$ \\ ${ }^{1}$ School of Urban Planning and Design, Peking University Shenzhen Graduate School, Shenzhen 518055, China \\ ${ }^{2}$ Shenzhen Talents Housing Group Co. Ltd, Shenzhen 518000, China \\ ${ }^{3}$ Xiamen Rail Transit Group Co. Ltd. Operation Branch, No. 166, Jixing Sea Wall Road, Jimei District, Xiamen, China
}

Correspondence should be addressed to Lei Zhang; zhanglei01@pku.edu.cn

Received 8 April 2021; Revised 11 May 2021; Accepted 31 May 2021; Published 24 June 2021

Academic Editor: Zhihan Lv

Copyright (c) 2021 Lei Zhang and Xueqing Hu. This is an open access article distributed under the Creative Commons Attribution License, which permits unrestricted use, distribution, and reproduction in any medium, provided the original work is properly cited.

\begin{abstract}
In the Guangdong-Hong Kong-Macao Greater Bay Area (Bay Area), the allocation methods of public rental housing are analyzed to achieve scientific and fair housing allocation as much as possible, so as to protect the housing demand of lowincome and middle-income families. The housing model in the Bay Area is analyzed firstly, and the key points of public rental housing and allocation management models are discussed comprehensively. Furthermore, a method based on rough-based fuzzy clustering (RFC) is proposed to analyze the housing demands of security groups, and a public housing allocation model is constructed based on actual demand of residents. The housing allocation plan is given and decided by the decision-making department based on the demand of the security objects and the characteristics of public housing. The simulation experiments are performed on the clustering algorithm optimized based on rough set feature selection. On the Chess data set, the optimized clustering algorithm shows an obvious improvement in clustering accuracy and recall rate compared with the traditional clustering algorithms, which are 0.76 and 0.95 , respectively. The bilateral matching method based on fuzzy axiom design can fully consider the actual needs of both the supply and demand of the housing security, which is beneficial to improve the rationality and correctness of public housing allocation. The allocation method of public housing based on demand clustering analysis focuses on improving the housing security level and strives to meet the higher-level housing improvement needs of housing security objects, so as to provide security objects with more expected living conditions and improve housing allocation effect.
\end{abstract}

\section{Introduction}

At the Fifth Session of the $12^{\text {th }}$ National People's Congress in March 2017, it was clearly pointed out that "the Mainland has to deepen cooperation with Hong Kong and Macao to fully play their unique advantages." The development plan for the city cluster in Bay Area was firstly compiled, which marked that the construction of Bay Area was deemed as a national strategy [1]. The cluster of nine cities in Hong Kong, Macao, and Guangdong Province is among the most open and economically vigorous regions in China, and it has critically strategic position in the overall situation of national development [2]. Guangdong, Hong Kong, and Macao have obvious comparative advantages and abundant stock resources. The implementation of the national strategy in the Bay Area provides a major opportunity for the three places to explore reforms, break through barriers, and transform existing resources into incremental resources. Guangdong is the frontier of opening up to the outside world in China and is the largest economic province, the largest foreign trade province, and the leading province with advanced manufacturing base and talents. In addition, Guangdong is one of the provinces with the highest degree of internationalization, marketization, and openness in China. In particular, it is forming a science and technology innovation corridor based on the advantages of the three places $[3,4]$. According to the protocol, Guangdong, Hong Kong, and Macao will build a world- 
class bay area and a city cluster with the support of relevant central authorities.

At present, the economic development level of the Bay Area exerts the leading role in the whole country, with a complete industrial system and supporting capabilities, obvious advantages in the development of industrial clusters, strong economic complementarity, and a cluster of innovative enterprises and elements. According to the development outline of the Bay Area, it is necessary to further clear the barriers among cities to allow the elements to flow more freely, which will inevitably have a profound impact on the real estate market in the Bay Area. The difference from other bay areas is that there are three different housing models in the Bay Area [5]. Guangzhou is a market dominated by housing transactions, Shenzhen market is dominated by second-hand and leasing, and Hong Kong market is dominated by the second-hand housing and public housing. However, the huge urban housing demand cannot be met by the traditional housing sales and leasing alone with the acceleration of the process of large-scale urbanization. The housing security system for low-income and middle-income groups has to be further improved. How to distribute the public housing to security groups with different needs in a fair and efficient manner is a key issue to be resolved at present. Some scholars used 3D geographic information system and cloud computing to propose a government affairs service platform, on which a series of e-government services can be realized, including the distribution of public housing $[6,7]$. Zou et al. analyzed the public elements involved in public housing and proposed 5 public housing allocation models, including administrative rationing, queuing, public participation, market filtering, and private developer sales [8].

The core of public housing construction and management lies in fairness and openness. Unclear residential housing demand and unscientific public housing allocation are critical reasons for ineffective public housing allocation $[9,10]$. After a reasonable public housing allocation system is formulated, residents can supervise government behaviors based on pre-judgment, which helps ensure the openness and transparency of housing allocation procedures, and enhance the credibility of government in the allocation process and results. In this article, the housing model in the Bay Area is analyzed firstly, and then the housing demands of the security groups are explored with the RFC method. The influencing factors of urban residents' willingness to improve housing conditions and the differentiation of housing choices are analyzed by modelling, and a multiobjective optimization decision-making model is established for matching and allocation of public housing based on the housing demand. Finally, the source of the imbalance in the supply and demand structure of public rental housing construction and allocation is analyzed by taking Shenzhen as an example, aiming to put forward reasonable suggestions for the improvement of the system. The innovation of this study is embodied in the use of relevant quantitative models in operational research optimization and decision science to give a feasible housing allocation plan. The value of the research lies in providing a scientific, effective, automated, and intelligent personnel-house allocation program for the distribution of public housing in China, so as to make up for the various shortcomings caused by the existing random lottery housing distribution method.

\section{Materials and Methods}

2.1. Housing Mode under the Structure of Guangdong-Hong Kong-Macao Greater Bay Area. 8 of the 11 cities in the Bay Area have a housing ownership rate of lower than $60 \%$, of which Shenzhen is only $23.7 \%$. The per capita living areas of the three core cities (Hong Kong, Shenzhen, and Guangzhou) are still far from the national average. It is estimated that by 2025 the transaction scale of the real estate market in the Bay Area will be about 3.7 trillion yuan, accounting for $15 \%$ of the total transaction volume in China [11]. According to the absolute level of housing prices, the urban housing prices in the Bay Area can be divided into three echelons: Hong Kong and Macau are the first echelon, with an average price of more than 100,000 yuan; the second echelon includes Shenzhen and Guangzhou, with an average price of more than 30,000 yuan (the average price in Shenzhen is more than 50,000); and other cities are included in the third echelon. In general, housing prices in cities in the Bay Area are imbalanced. Comparison on housing prices in the three core cities reveals that the absolute level of housing price in Guangzhou is lower, the ratio of housing prices to income $(\mathrm{HP} / \mathrm{I})$ is relatively low, and the increase rate in housing prices is relatively weak; the absolute level of housing price in Shenzhen is 7 times that in Guangzhou with the highest HP/I and the fastest increase rate, while the absolute housing price in Hong Kong ranks among the top international cities, and is 2.7 times of that in Shenzhen, but its increase rate is lower than Guangzhou and Shenzhen, so the income from housing sales is between that of the Guangzhou and Shenzhen. The predicted housing transaction scale in the Bay Area in 2025 is shown in Table 1.

Guangzhou market is dominated by housing transactions, and the supply of new houses and second-hand houses is relatively balanced. The supply of new houses in Guangzhou is relatively sufficient to meet the demand for improved house swaps, and house prices are relatively friendly to first-time buyers, so the pressure on house prices is not so great. Shenzhen is a market dominated by secondhand and leasing. The housing ownership rate in Shenzhen is low. Due to the insufficient supply of new houses, the transaction multiplier of second-hand houses is large, and house prices tend to rise rapidly [12]. In 2018, the gross merchandise volume (GMV) in Shenzhen accounted for $30 \%$ of the overall real estate market, surpassing the GMV of new house transactions. From the perspective of the housing stock structure in Shenzhen, $65 \%$ of the rental housing is provided by urban villages. Unlike mainland cities, public housing provided by the government and public institutions occupies an important position in the Hong Kong rental market. In 2016, 45\% of Hong Kong people lived in public housing, and nearly $30 \%$ of the population lived in public rental housing provided by the government, which was greater than the proportion of the population renting in 
TABLe 1: The predicted housing transaction scale in the Guangdong-Hong Kong-Macao Greater Bay Area in 2025.

\begin{tabular}{lccc}
\hline Transaction volume $(100$ million) & 2018 & 2025 & Average annual growth rate (\%) \\
\hline New house & 11243 & 15323 & 4.5 \\
Second-hand house & 12918 & 21852 & 7.8 \\
Total & 24161 & 37175 & 6.3 \\
Proportion of second-hand houses (\%) & 53.5 & 58.8 & 0.75 \\
\hline
\end{tabular}

Data source: estimation of Beike Institute.

private rental housing. Compared with other cities, the proportion of private rental market in Hong Kong is lower, with only $17 \%$ of households living in the private rental market $[13,14]$. Macau has an area of about 27 square kilometers and a population of about 460,000 . Social housing is a residential unit used for rent in public housing, and the targets are low-income families or families with special difficulties. The government investigates the income of lowincome families every two years. Generally speaking, rent accounts for 5-15\% of household income. But if the family income is lower than a certain standard, the rent can be lower than $2.5 \%$ of the family income, while if the family income is higher than a certain standard, the rent can reach $17.5 \%$ of the family income. Owners of economic houses must live on their own in accordance with the law and have a "non-transferable liability" period. If the purchase family enjoys the allowance, the unit cannot be transferred within 12 years from the date of obtaining the right to use. Due to the relatively developed economy of Macau and the early implementation of public housing policies, the higher expectations of policy makers are to further improve the public housing policies to achieve the goal of "housing for homes."

The White Paper pointed out that the housing problems in the core cities of the Bay Area are mainly the housing difficulties of the migrant population and the young population, which are mainly manifested in the unaffordable housing and poor living quality. Among the 11 cities in the Bay Area, Shenzhen and Hong Kong have the highest HP/Is, of which the urban villages in Shenzhen account for nearly half of the total stock, and housing about 15 million people, so the living environment of this group of people has to be improved [15]. In addition, a thorough marketization path has been implemented in Shenzhen after the housing reform. The current housing stock of affordable housing (economically affordable housing + public rental housing) accounts for only $4.1 \%$, so the housing security channels have to be further strengthened. In the future, the way to break the real estate situation in the Bay Area is to rebalance the relationship between the market and security. The core is that the government guides the market to increase effective supply and change the imbalance of market structure. The real estate market in the Bay Area should be diversified, including developers, enterprises, governments, and farmers; the guarantee channels can look for the supply in stock market and surrounding cities besides the incremental market [16].

2.2. Public Rental Housing and Allocation Management Model. Public rental housing is a kind of security system, which is quasi-public and social security. As a government public welfare construction project, public rental housing requires a large amount of funds and a long construction period, so the government needs strong funding support [17]. The property rights belong to the government or public institutions, and the unit type and area are limited. The eligible low-income and middle-income families with housing difficulties can rent the public rental housing at the price slightly lower than the market rent. After the merger of public rental housing and low-cost housing, the two are collectively referred to as public rental housing $[18,19]$. The guarantee objects of public rental housing include migrant workers, fresh graduates, entrepreneurs, and other low-income and middle-income families with housing difficulties. At present, the security objects of co-rental housing are also included in those of the previous low-rent housing. Compared with the two types of affordable housing (affordable housing and price-limited commercial housing), the coverage of the updated public rental housing is shown in Figure 1.

The property rights of public rental housing are owned by the national government. After the lease term expires, eligible tenants are allowed to purchase the public rental housing at the specified price, but are not allowed to rent, transfer, or give away. This also avoids unfair housing allocation caused by property rights and ensures that most housing circulates within the system. The circulation rules of public rental housing are shown in Figure 2. Based on the theory of government intervention, a special housing management agency should firstly be set up in order to achieve a fair allocation of housing resources; in addition, other private enterprises can be considered to participate in the construction and operation of housing, so as to form a joint and health competition with the exclusive management agency for public rental housing, improving the efficiency of government intervention in housing management [20].

Most applicants applying the affordable housing have a stable source of income, but they are still difficulties in solving the family housing. Therefore, the premise of formulating a reasonable housing security policy is to assess the housing affordability of residents [21, 22]. In terms of household income restrictions, there is no uniform standard for the definition of income scopes in various regions. Since a large part of public rental housing construction funds come from government subsidies, all parts in China determine the rents basically based on housing construction, operation, and management costs, which is slightly lower than the market rent level. On the other hand, it is rare to determine the price based on the ability to pay of the renter. Even some cities fail to include the tenant's ability to pay into the public rental housing rent- 


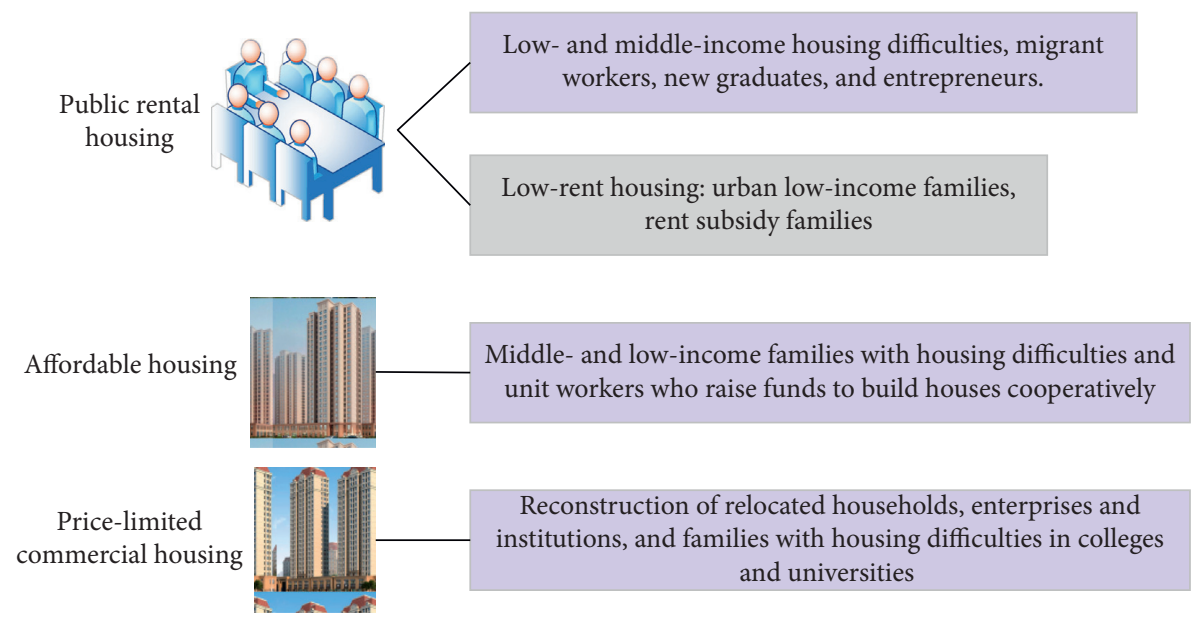

FIGURE 1: The coverage of security objects of the three types of housing.

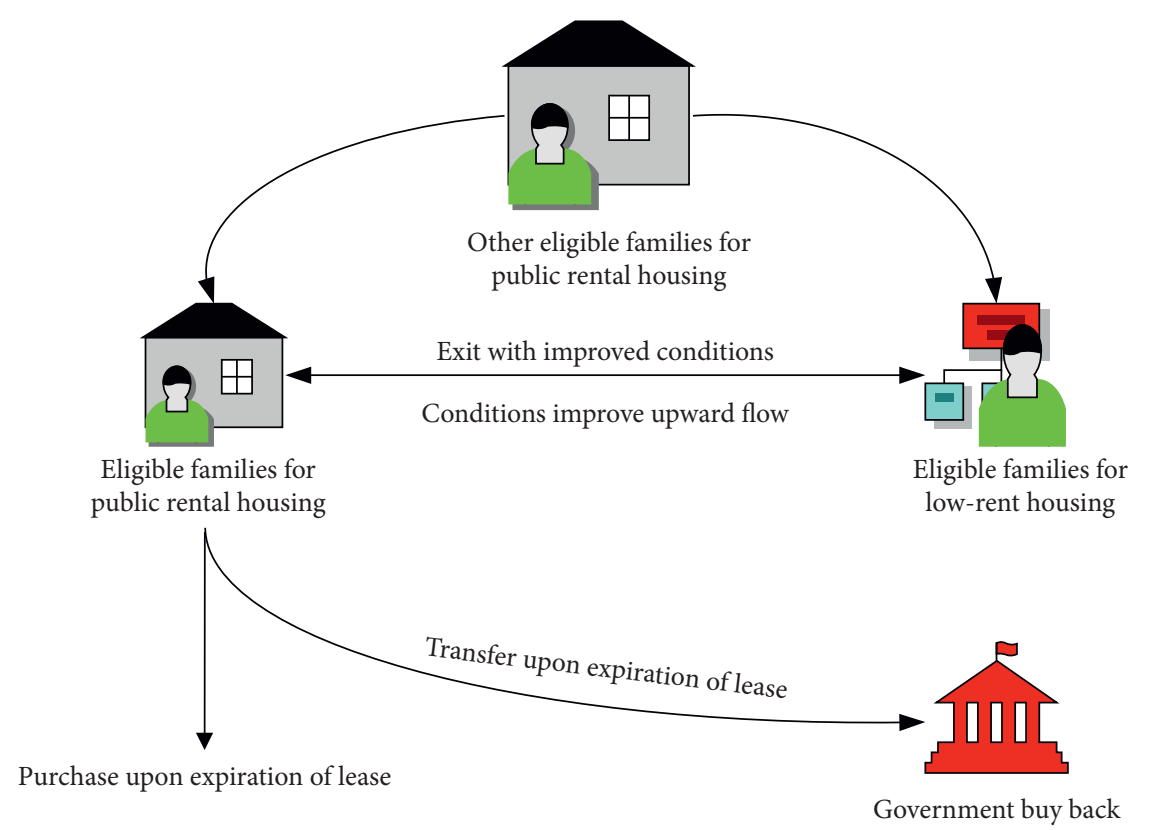

FIgURE 2: The circulation rules of public rental housing.

setting standards. As the rent expenditure exceeds their actual affordability, some families fail to receive the security they deserve. Large-scale housing projects require a large amount of financial support, and government financial subsidies alone are far from enough. It is necessary to develop new financing models and expand the funding sources for public housing construction.

\subsection{Residential Housing Demand Recognition Model Based on} Fuzzy Clustering. Before the housing allocation, it is necessary to understand the number of people with housing difficulties and their specific housing demand. The number of houses that can be provided in the current environment should be known clearly. Only when these two points of information are accurate and clear can the housing security plans be formulated reasonably to meet the multi-level needs of families and individuals with housing difficulties [23]. The early public housing allocation plan fails to incorporate the needs of residents into the allocation principle. It is basically dominated by the housing supply, and the allocation is realized according to the current actual situation, which also ignores the psychological expectations of the security population.

For the analysis of consumer demand in the product market, the clustering method is an important data mining method. The cluster analysis divides the customers according to their needs, preferences, values, and other factors, so that the development strategy of the enterprise and the category of targeted services provided to customers can be clarified enough [24]. Correspondingly, only when understanding the actual housing demand of residents can the objects of housing demand be effectively clustered and divided to provide a basis for the formulation and 
implementation of affordable housing planning in the field of affordable housing for residents. Combined with the housing census questionnaire in China, the demographic characteristics and current housing conditions are selected as the elements to construct the indicator system in this study. On one hand, it is necessary to collect information such as the population's household registration information, the number of permanent residents in the family, and the average monthly income per capita. On the other hand, it is necessary to collect the nature of the housing, the complete set of the housing, the year when the housing is built, the integrity of the housing, the type of housing, ownership, and housing area per capita. The above-mentioned characteristics are undertaken as sample attribute dimensions to construct a residential housing demand recognition model, as shown in Figure 3.

Generally, there are many feature attributes for clustering objects and there is a very obvious correlation among each other. However, too much redundant information will affect the clustering progress and the clustering speed. In the initial feature selection link, the features should be selected as least as possible, and the most representative information has to be highlighted [25]. In this case, it can simplify the clustering process and improve the accuracy of clustering. Neighborhood rough set can complete the processing of numerical and sub-type features, so the model based on neighborhood rough set has better applicability to mixed heterogeneous data of housing features. Therefore, the method based on neighborhood rough set is adopted in this study to reduce the characteristic attributes of residential housing demand. The structured data for clustering can usually be regarded as an information system, which can be expressed as $I S=\langle U, A\rangle$, of which $U=\left\{x_{1}, x_{2}, \ldots, x_{n}\right\}$ represents a non-empty finite set; $A=\left\{a_{1}, a_{2}, \ldots, a_{m}\right\}$ is an attribute set of sample characteristics. When $A=C \cup D$, IS can be called a decision table. $C$ represents the condition attribute set, and $D$ is the decision attribute.

$x_{i} \in U$ and $B \subseteq C$ are given, of which $B$ represents the feature space. The neighborhood $\delta\left(x_{i}\right)$ of $x_{i}$ in $B$ can be defined with the following equation:

$$
\delta\left(x_{i}\right)=\left\{x_{j} \mid x_{j} \in U, \Delta_{B}\left(x_{i}, x_{j}\right) \leq \delta\right\} .
$$

In the above equation, $\Delta$ is a distance measurement function, representing the maximum distance from the center point of the neighborhood to the boundary, and $\forall x_{1}, x_{2}, x_{3} \in U$ satisfies the following equations:

$$
\begin{aligned}
& \Delta\left(x_{1}, x_{2}\right) \geq 0, \\
& \Delta\left(x_{1}, x_{2}\right)=0, \\
& \Delta\left(x_{1}, x_{2}\right)=\Delta\left(x_{2}, x_{1}\right), \\
& \Delta\left(x_{1}, x_{3}\right) \leq \Delta\left(x_{1}, x_{2}\right)+\Delta\left(x_{2}, x_{3}\right) .
\end{aligned}
$$

$B_{1} \subseteq A$ and $B_{2} \subseteq A$ are set to the numerical and sub-type attribute sets in $A$, respectively; then, the neighborhood particles of the sample $x$ generated in the feature space can be written as follows:

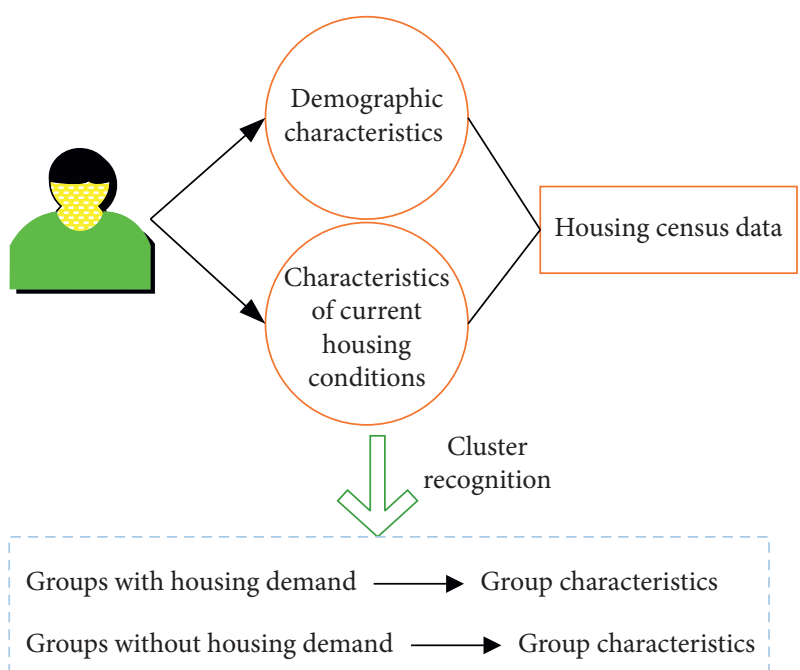

Figure 3: A residential housing demand recognition model.

$$
\begin{aligned}
\delta_{B_{1}}(x) & =\left\{x_{i} \mid \Delta_{B_{1}}\left(x, x_{i}\right) \leq \delta, x_{i} \in U\right\}, \\
\delta_{B_{2}}(x) & =\left\{x_{i} \mid \Delta_{B_{2}}\left(x, x_{i}\right)=0, x_{i} \in U\right\}, \\
\delta_{B_{1} \cup B_{2}}(x) & =\left\{x_{i} \mid \Delta_{B_{1}}\left(x, x_{i}\right) \leq \delta \wedge \Delta_{B_{2}}\left(x, x_{i}\right)=0, x_{i} \in U\right\} .
\end{aligned}
$$

Then, a neighborhood relationship matrix $N$ can be generated to indicate the binary relationship of each element in $U$. The corresponding relationship matrix can be expressed as the following equations:

$$
\begin{gathered}
M(N)=\left(r_{i j}\right)_{n \times n}, \\
r_{i j} \begin{cases}1, & \Delta\left(x_{i}, x_{j}\right) \leq \delta, \\
0, & \text { other. }\end{cases}
\end{gathered}
$$

If there is an attribute in the system that can produce a neighborhood relationship within the overall, then the neighborhood system can be expressed as NIS $=\langle U, A, N\rangle$. The neighborhood model can divide samples into two subsets: positive domain and boundary domain. Positive domain refers to a collection of samples that can be classified into a certain decision category, and boundary domain refers to a collection of samples that cannot be clearly classified. According to the variable precision rough set theory, the neighborhood rough set can be defined by a measure of the degree of inclusion. If two sets $A$ and $B$ are given in $U$, the degree of $A$ to be included in $B$ can be expressed as equation (10):

$$
I(A, B)=\frac{\operatorname{Card}(A \cap B)}{\operatorname{Card}(A)} .
$$

The traditional clustering methods are usually only suitable for the clustering of numerical features. If the categorical features are converted into numerical features, some meaningless clustering categories can be produced in 
the process. A neighborhood system realized by neighborhood granulation is introduced in this study, which can process the discrete continuous data sets effectively based on neighborhood through the neighborhood rough set. If the neighborhood rough set model is adopted to replace the traditional rough equivalent approximation relationship model, continuous data can be processed directly without discretization, thereby avoiding information loss in the discretization process.

\subsection{Public Housing Allocation Model Based on Demand of} Residents. The public rental housing in China currently is allocated in two ways: (1) supplying monetary subsidies for families who meet the conditions for applying for public rental housing to alleviate the shortage of public rental housing from another perspective; (2) adopting physical rent allocation to solve housing difficulties for low-income and middle-income families. The second type of public housing allocation method is featured with complex preliminary investigation, long application and review procedures, and mixed rent of households with different needs in turn, so that the housing allocation efficiency is low, residents cannot be secured timely, and the overall satisfaction is not high.

The public housing involves three subjects in general: security objects, public housing, and decision-making department. The needs of housing security objects for public housing attributes are reasonable. Firstly, the security objects have the housing attributes needs; secondly, the housing attribute needs of housing security objects cannot exceed the local housing security standards [26]. The housing allocation plan is given and decided by the decision-making department based on the demand of the insured objects and the characteristics of public housing. The allocation of public housing is shown in Figure 4. The security objects and public housing are located at two nodes on the left and the right. The connecting line between the two indicates the possible and actual results of allocation. The purpose of housing allocation is to determine the matching relationship between the connecting line and the node sand maximize the degree of matching between the two.

A multi-objective optimization model that maximizes the matching degree of public housing to security needs is designed and constructed based on the independence axioms and information axioms. If the information capacity of the attribute $A_{j}$ is set to $I_{j}$, the calculation of $I_{j}$ can be expressed as follows:

$$
I_{j}=\log _{2} \frac{1}{p_{j}} .
$$

In equation (11), $p_{j}$ refers to the probability of success in fulfilling the functional requirements, which can be regarded as a function between satisfying the design scope and the actual scope. The design scope reflects the expected value of the demand attribute, which can be also determined as the ideal expected level of housing demand of the security object; the actual scope actually refers to the actual output of the public housing attribute. The part where the design scope and the actual scope overlap is the public scope, which

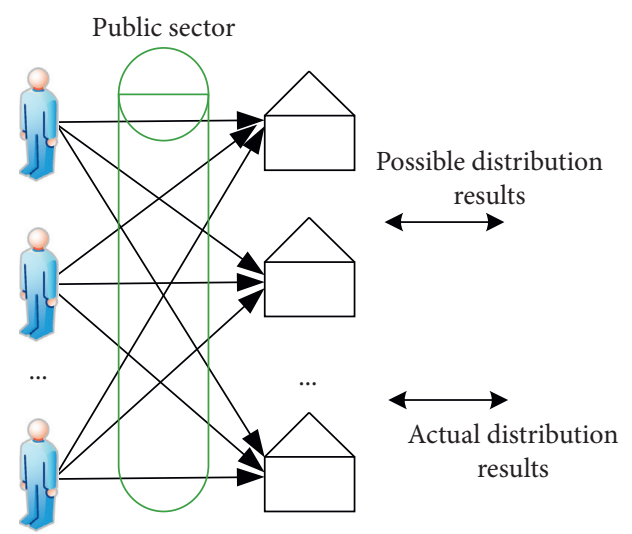

Figure 4: The allocation of public housing.

reflects the degree of matching between the expectation and reality of the attribute, referring to the overlap between the ideal scope of residential housing demand attributes and the actual output of public housing attributes. The basic division of design scope, actual scope, and public scope in axiomatic design can be obtained based on the $I_{j}$ and $p_{j}$, as shown in Figure 5. When the actual scope fails to meet the design scope, it means that the actual output of the public housing attribute does not meet the ideal demand of residents for housing attributes. At this time, the information capacity of the attribute can be written as $I_{j}=\infty$. When the actual scope completely exceeds the design scope, it means that the actual output of the public housing attribute fully meets the housing attribute needs of residents, and the information capacity of this attribute can be recorded as $I_{j}=0$.

According to the fuzzy axiom design principle, the fuzzy design scope should reflect the expected fuzzy value of the demand attribute, which is the ideal fuzzy scope of the housing demand attribute of the residents; fuzzy reality means the actual fuzzy output of the public housing attribute; fuzzy public scope refers to the overlap between the actual fuzzy output of public housing attributes and the ideal fuzzy scope of residential housing demand attributes. The basic division of fuzzy design scope, fuzzy actual scope, and fuzzy public scope based on fuzzy axioms is shown in Figure 6.

Based on the calculation of the matching degree of fuzzy axiom design, a calculation method of function surplus is presented based on fuzzy information in this study, as follows:

$$
d_{i, k, j}= \begin{cases}0, & t_{k j}^{R} \leq r_{i j}^{L}, \\ \int_{r_{i j}^{L}}^{t_{k j}^{R}} \mu_{t}(x) \mathrm{d} x, & t_{k j}^{R}>r_{i j}^{L} .\end{cases}
$$

In the above equation, $t_{k j}^{R}$ represents the actual output value of the $j$ th housing attribute of the kth public housing, and $R$ refers to the guarantee object-housing attribute demand matrix.

The equation means that the part of the fuzzy system range is out of the fuzzy design range. It means that the function value is excessive if the fuzzy system range is on the 


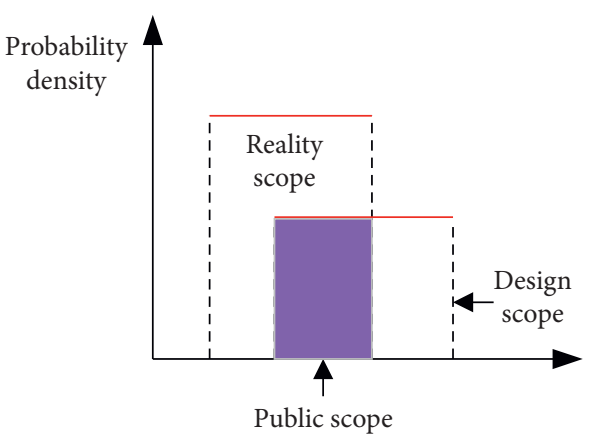

FIgURE 5: Basic division of housing in the axiomatic design.

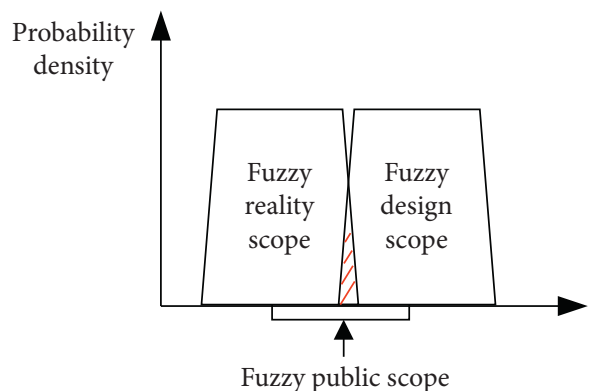

FIGURE 6: Basic division of housing in the fuzzy axiomatic design.

right side of the left side of the fuzzy design range, while if the provided fuzzy system range is on the left side of the left side of the fuzzy design range, the matching degree is 0 and its excess function value is also 0 in the fuzzy axiom design.

\subsection{Analysis and Model Application of Improved Clustering} Algorithm. In this study, Chess, Lung-Cancer, and Soybean are selected to verify the effectiveness of the improved clustering algorithm, and the clustering results of the data set based on rough set feature selection are compared with the original cluster analysis. The clustering algorithm is utilized to cluster the data set to obtain the initial class label and the initial clustering accuracy firstly; then, the proposed feature selection algorithm based on the neighborhood rough set is adopted to select a feature subset, which is clustered again to obtain the new classification precision. After the original data set was clustered 100 times, the effectiveness of the proposed algorithm is verified in terms of accuracy, precision, recall, and standard deviation of the clustering.

In order to verify the usability of the housing allocation model, application information of 6 security objects $(\mathrm{P})$ that meets the public housing application conditions is given, and there are 8 public housings $(\mathrm{H})$ to be allocated. The server configuration of the housing security management system is given as follows: CPU of Intel Xeon E5-2690, memory of $16 \mathrm{~GB}$, built-in hard disk capacity of $500 \mathrm{~GB}$, and database platform of Structured Query Language (SQL) server. The housing attribute characteristics of public housing are consistent with the dimensions of the housing demand attributes of the guarantee objects. The housing price $A_{1}$, housing area $A_{2}$, housing location $A_{3}$, housing floor $A_{4}$, and property condition $A_{5}$ are undertaken as the attribute basis for public housing allocation. Among them, housing price and housing location are cost attributes, housing area belongs to the income attributes, housing floor is a hard-bound attribute, and property condition is a fuzzy language evaluation attribute. The weight of the security urgency of the resident is set to $W=(0.1,0.15,0.4,0.05,0.1,0.2)$, and the weight vector of the public housing attributes can be $\alpha=(0.4,0.25 .0 .15,0.1,0.1)$.

\section{Results and Discussion}

3.1. Performance of Feature Selection Clustering Algorithm Based on Rough Set. The performance of the rough set-based feature selection clustering algorithm is verified on three data sets: Chess, Lung-Cancer, and Soybean, and the results are shown in Figures 7-9, respectively. After the original data set is selected by the feature selection algorithm based on rough set mentioned in this study, the cluster analysis on the obtained feature subset shows that the indicators are significantly better than those of the traditional clustering algorithm. This proves that the algorithm proposed can select feature subsets with higher classification accuracy. Analysis reveals that the clustering accuracy of the feature subsets on the Chess and Lung-Cancer data sets after feature selection based on the rough set has been significantly improved in contrast to the traditional clustering algorithm before optimization; the recall rate of the rough set-based feature selection clustering algorithm has been significantly improved on the in the Soybean data set. In summary, the experimental results show that the optimized clustering algorithm in this study can select effective feature subsets with clustering properties, which is of great significance for improving the clustering accuracy of the data set.

The clustering algorithm proposed can improve the accuracy of clustering results and can also select a subset of features with higher classification accuracy. The condition characteristics of public housing and the demand characteristics of guarantee objects can improve the classification effect and lay a foundation for the subsequent matching of housing conditions and object needs.

3.2. Validation on Housing Allocation Model from the Perspective of Demand. The expectation level of a group of security objects for the public housing attributes is given based on the actual demand, as shown in Table 2 below. Table 3 shows the actual output information of the existing public housing attributes. The information capacity of each public housing for each security object is calculated according to the housing allocation model, and the results are disclosed in Table 4. Based on the axiom design theory, it reflects the matching degree of public housing to meet the needs of guarantee objects in prospective of demand. From the perspective of the actual application of housing security, this demand analysis method reflects the ability of public housing to meet the needs of the security target, and the part of the housing attribute of public housing that exceeds the needs of the security target, which together reflects the level 


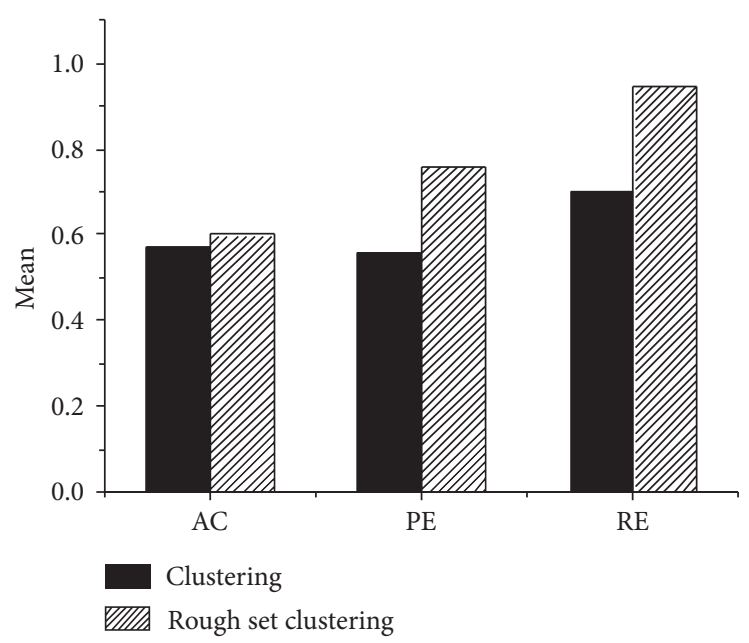

FIGURE 7: Comparison on performance of clustering algorithm on the Chess data set. Note: AC, PE, and RE in the figure refer to accuracy, precision, and recall, respectively.

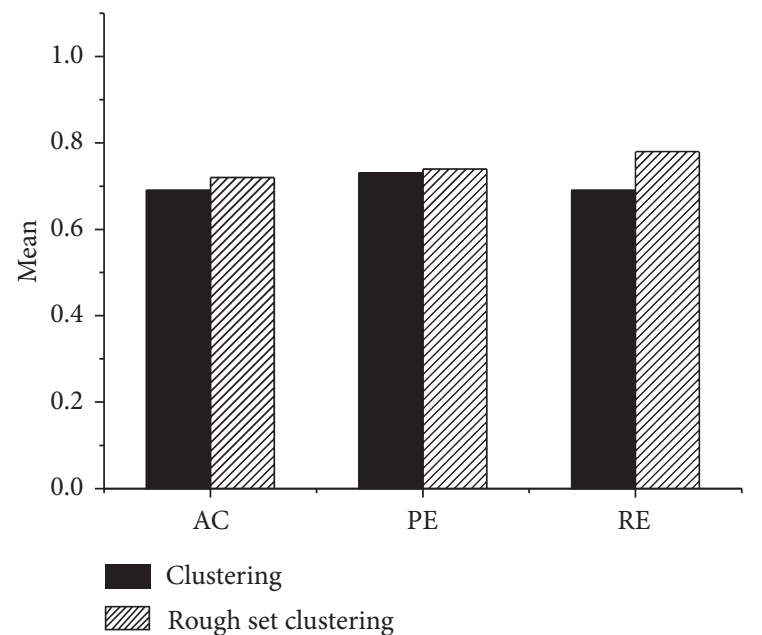

FIGURE 8: Comparison on performance of clustering algorithm on the Lung-Cancer data set.

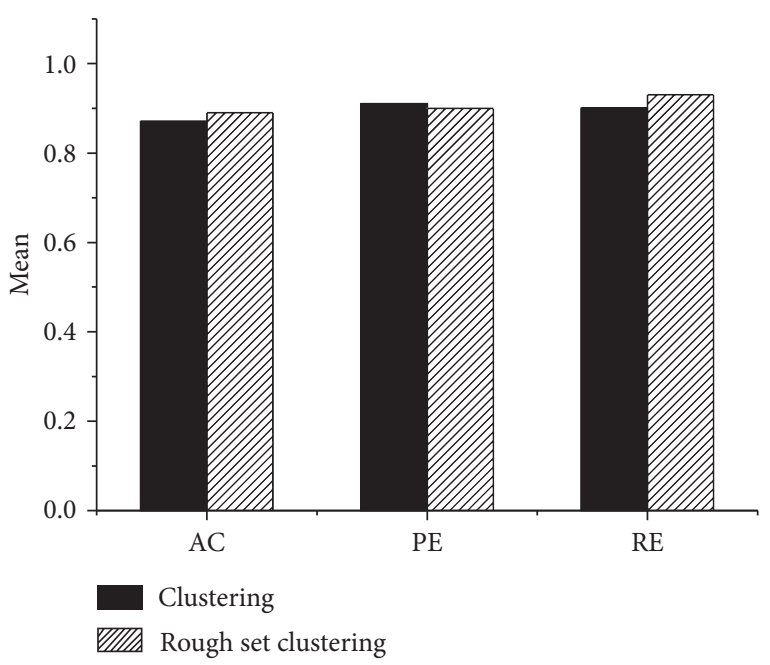

FIgURE 9: Comparison on performance of clustering algorithm on the Soybean data set. of housing security. From the practical sense of housing security, fuzzy axioms reflect the ability of public housing to meet the needs of security objects and reflect the level of housing security. When housing supply is tight, housing security funds are limited, and the number of housing security objects is too large, priority has to be given to higher security coverage to meet the basic housing needs of households with housing difficulties as much as possible and to increase the number of matched allocations. When the housing security development is mature and complete and the proportion of housing security objects "living in a place" is high, attention has to be paid to improving the security level of housing security and trying to meet the higher-level housing improvement needs of housing security objects. In the distribution, public housing with better living conditions and more complete supporting facilities will be provided for guarantee objects.

Based on the abovementioned housing allocation model, the allocation of public rental housing in Shenzhen is planned under the pattern of the Bay Area. When the supply of public housing is less than demand, it can be allocated by lottery, which can effectively save administrative costs while avoiding the interference of human factors. However, randomness of the lottery cannot reflect the principle of giving priority to the weak, and poor residents are likely to fail the lottery many times, which is unfair. Therefore, it is necessary to improve the lottery distribution system, such as distinguishing different types of applicants (including the first-time applicants and applicants who want to trade-in), and appropriately improving the rules so that the first-time applicants can receive priority security. For families who have participated in the lottery many times but have failed to apply for housing, the government can provide additional housing to ensure the principle of relative equality as much as possible. Not only that, Shenzhen can try to improve the housing allocation method of the lottery, such as lottery in batches according to the urgency of the applicants' needs and the income level indicators, so as to give priority to guaranteeing the opportunities for lower-income applicants. 
TABLE 2: The expectation level of a group of 6 security objects for the public housing attributes.

\begin{tabular}{lccccc}
\hline Guarantee object & A1 $\left(\right.$ yuan $\left./ \mathrm{m}^{2}\right)$ & A2 $\left(\mathrm{m}^{2}\right)$ & A3 $(\mathrm{km})$ & \multicolumn{1}{c}{ A4 (floor) } & A5 (property) \\
\hline P1 & $6 \sim 9.2$ & $30 \sim 40$ & $5 \sim 10$ & $1 \sim 5$ & Middle \\
P2 & $7.1 \sim 8.1$ & $40 \sim 55$ & $10 \sim 15$ & $4 \sim 7$ & Senior \\
P3 & $3.5 \sim 4.6$ & $30 \sim 45$ & $10 \sim 20$ & $1 \sim 5$ & Middle \\
P4 & $5.4 \sim 7.5$ & $45 \sim 60$ & $15 \sim 20$ & $1 \sim 4$ & Middle \\
P5 & $8 \sim 10.4$ & $50 \sim 60$ & $10 \sim 15$ & $1 \sim 5$ & Senior \\
P6 & $9.2 \sim 10.3$ & $45 \sim 60$ & $15 \sim 25$ & 0.1 & Senior \\
$\alpha_{j}$ & 0.4 & 0.25 & 0.15 & & 0.1 \\
\hline
\end{tabular}

TABLE 3: The actual output information of attributes characteristics of the 8 public housings.

\begin{tabular}{|c|c|c|c|c|c|}
\hline Public housing & A1 $\left(\right.$ yuan $\left./ \mathrm{m}^{2}\right)$ & $\mathrm{A} 2\left(\mathrm{~m}^{2}\right)$ & A3 $(\mathrm{km})$ & A4 (floor) & A5 (property) \\
\hline $\mathrm{H} 1$ & $5 \sim 7.3$ & 44 & 8 & 5 & Middle \\
\hline $\mathrm{H} 2$ & $3.5 \sim 6.5$ & 32 & 6 & 6 & Middle \\
\hline $\mathrm{H} 3$ & $4.3 \sim 4.9$ & 54 & 10 & 3 & Middle \\
\hline $\mathrm{H} 4$ & $6.1 \sim 8.5$ & 36 & 15 & 4 & Middle \\
\hline H5 & $7.2 \sim 9.1$ & 40 & 18 & 2 & Senior \\
\hline H6 & $5.3 \sim 7.7$ & 65 & 22 & 1 & Senior \\
\hline $\mathrm{H} 7$ & $2.5 \sim 3.9$ & 37 & 17 & 5 & Middle \\
\hline $\mathrm{H} 8$ & $7.5 \sim 10.2$ & 72 & 15 & 6 & Senior \\
\hline$\alpha_{j}$ & 0.4 & 0.25 & 0.15 & 0.1 & 0.1 \\
\hline
\end{tabular}

TABle 4: Actual output information for attribution characteristics of 8 public housings and 6 security objects.

\begin{tabular}{llccccc}
\hline Public housing & P1 & P2 & P3 & P4 & P5 & \\
\hline H1 & $\infty$ & 0.2320 & $\infty$ & $\infty$ & $\infty$ & $\infty$ \\
H2 & $\infty$ & $\infty$ & 0.0235 & $\infty$ & 0 & $\infty$ \\
H3 & $\infty$ & 0.0246 & $\infty$ & 0.0815 & 0.0368 & $\infty$ \\
H4 & $\infty$ & $\infty .0740$ & $\infty$ & $\infty$ & $\infty$ & 0.0370 \\
H5 & $\infty$ & $\infty$ & $\infty$ & $\infty$ & 0 \\
H6 & $\infty$ & $\infty$ & $\infty$ & $\infty$ & $\infty$ \\
H7 & $\infty$ & $\infty$ & $\infty$ & $\infty$ & $\infty$ \\
H8 & $\infty$ & $\infty$ & & $\infty$ & $\infty$ \\
\hline
\end{tabular}

The matching utility of public housing can linearly decrease with the increase in the preference order of the guaranteed family. The housing allocation model in this article is based on the theory of bilateral matching, and it takes into account the preference sequence information of the security groups and public housing, expanding the unilateral decision-making matter into a bilateral decisionmaking matter. Based on the description of the multi-attribute matching of housing security objects and public housing in the distribution of public housing, the rules of public housing distribution are designed. This method can fully consider the matching requirements of the housing security supply and demand parties, is conducive to improving the science, rationality, and correctness of public housing matching and distribution, and has reliable feasibility and applicability.

\section{Conclusion}

As a node along the national "One Belt One Road" route, the Bay Area exerts significant roles. With the rapid development of the real estate market in the Bay Area, the livelihood security of residents is also an issue that cannot be ignored. It is related to social stability and people's quality of life. Under the situation that government resources are heavily tilted, the construction value of public rental housing has initially appeared, but only a reasonable allocation of public rental housing can achieve the ultimate guarantee achievement.

A feature selection clustering algorithm is proposed based on rough set and is compared with the traditional clustering algorithms in this study. On the three data sets, the optimized clustering algorithm has higher performance indicators, which is significantly better than those of the traditional clustering similar algorithms. It indicates that the clustering algorithm based on rough set can not only effectively improve the clustering accuracy, but also select the feature subset with higher classification precision. After preliminary analysis of the housing demand of the security objects through clustering, the housing allocation model is explored and discussed in this study. The bilateral matching method based on fuzzy axiom design can fully consider the actual needs of both the supply and demand of housing security, can complete the matching, and is conductive to improving the rationality and correctness of housing allocation. Thus, it is feasible and applicable. Limited to the research focus of this article, it does not introduce in detail 
technologies such as information collection and storage, heterogeneous database exchange, and GIS geographic information systems that protect families and public housing. In the actual housing distribution work, it is highly dependent on the application of mature information technology, so the integration of housing distribution and information technology is an important direction for future research.

\section{Data Availability}

The data used to support the findings of the study are available from the corresponding author upon request.

\section{Conflicts of Interest}

The authors declare that they have no conflicts of interest.

\section{References}

[1] Y. Zhou, Y. Shan, G. Liu, and D. Guan, "Emissions and lowcarbon development in Guangdong-Hong Kong-Macao greater Bay area cities and their surroundings," Applied Energy, vol. 228, pp. 1683-1692, 2018.

[2] P. Ma, W. Wang, B. Zhang et al., "Remotely sensing large- and small-scale ground subsidence: a case study of the Guangdong-Hong Kong-Macao greater Bay area of China," Remote Sensing of Environment, vol. 232, Article ID 111282, 2019.

[3] P. Wu, Y. Tang, M. Dang et al., "Spatial-temporal distribution of microplastics in surface water and sediments of maozhou river within Guangdong-Hong Kong-Macao greater bay area," Science of the Total Environment, vol. 717, Article ID 135187, 2020.

[4] L. Lixun, "Thinking on the Guangdong-Hong Kong-Macao greater bay area," Tropical Geography, vol. 37, no. 6, pp. 757-761, 2017.

[5] H. Li, R. Jin, X. Ning, M. Skitmore, and T. Zhang, "Prioritizing the sustainability objectives of major public projects in the Guangdong-Hong Kong-Macao greater bay area," Sustainability, vol. 10, no. 11, Article ID 4110, 2018.

[6] Z. Lv, X. Li, W. Wang, B. Zhang, J. Hu, and S. Feng, "Government affairs service platform for smart city," Future Generation Computer Systems, vol. 81, pp. 443-451, 2018.

[7] Z. Lv, X. Li, H. Lv et al., "BIM big data storage in WebVRGIS," IEEE Transactions on Industrial Informatics, vol. 16, no. 4, pp. 2566-2573, 2019.

[8] Z. Zuo, W. Zhenwei, C. Kunlun et al., "The basic allocation modes of public housing-classification, comparison and enlightenment," China Real Estate, vol. 12, p. 8, 2015.

[9] R. Andersson and L. M. Turner, "Segregation, gentrification, and residualisation: from public housing to market-driven housing allocation in inner city Stockholm," International Journal of Housing Policy, vol. 14, no. 1, pp. 3-29, 2014.

[10] A. Pérez-Fargallo, C. Rubio-Bellido, J. A. Pulido-Arcas, and M. Trebilcock, "Development policy in social housing allocation: fuel poverty potential risk index," Indoor and Built Environment, vol. 26, no. 7, pp. 980-998, 2017.

[11] L. Zeng, "Study on the efficiency and the cooperative direction of tourism and leisure industry in Guangdong-Hong KongMacao greater bay area," Open Journal of Social Sciences, vol. 6, no. 01, pp. 93-105, 2018.

[12] Z. Chong and S. Pan, "Understanding the structure and determinants of city network through intra-firm service relationships: the case of Guangdong-Hong Kong-Macao Greater Bay Area," Cities, vol. 103, Article ID 102738, 2020.

[13] X. Wang, F. Yan, and F. Su, "Impacts of urbanization on the ecosystem services in the Guangdong-Hong Kong-Macao greater bay area, China," Remote Sensing, vol. 12, no. 19, Article ID 3269, 2020.

[14] M. Wen, C. Liu, P. Galina et al., "Efficiency analysis of the marine economy in the Guangdong-Hong Kong-Macao greater bay area based on a DEA model," Journal of Coastal Research, vol. 106, no. SI, pp. 225-228, 2020.

[15] X. Fang, Q. Fan, H. Li, Z. Liao, J. Xie, and S. Fan, "Multi-scale correlations between air quality and meteorology in the Guangdong-Hong Kong-Macau greater bay area of China during 2015-2017," Atmospheric Environment, vol. 191, pp. $463-477,2018$.

[16] W. Liao, X. Cao, and S. Li, "Competition and sustainability development of a multi-airport region: a case study of the Guangdong-Hong Kong-Macao greater bay area," Sustainability, vol. 11, no. 10, p. 2958, 2019.

[17] C. A. I. Xiang, "Determinants of affordable housing allocation: common perspectives from local officials," Regional Science Inquiry, vol. 10, no. 2, pp. 227-237, 2018.

[18] K. Suszyńska and Z. Rataj, "New trends in social housing allocation-case study (City of Poznań, Poland)," Urban Development Issues, vol. 56, no. 4, pp. 53-58, 2017.

[19] L. Zhang, T. Zhou, and C. Mao, "Does the difference in urban public facility allocation cause spatial inequality in housing prices? Evidence from chongqing, China," Sustainability, vol. 11, no. 21, p. 6096, 2019.

[20] J. Zhou and R. Ronald, "Housing and welfare regimes: examining the changing role of public housing in China," Housing, Theory and Society, vol. 34, no. 3, pp. 253-276, 2017.

[21] Z. Muhammad and F. Johar, "Critical success factors of public-private partnership projects: a comparative analysis of the housing sector between Malaysia and Nigeria," International Journal of Construction Management, vol. 19, no. 3, pp. 257-269, 2019.

[22] Y. Lahboub, E. M. Bachaoui, A. El Harti, and A. El Ghmari, "Multi-level cellular automata-based housing allocation model for small cities in developing countries: a case study of Kasba-Tadla city, in Morocco," International Journal of Urban Sustainable Development, vol. 10, no. 2, pp. 186-202, 2018.

[23] D. Czischke, "Collaborative housing and housing providers: towards an analytical framework of multi-stakeholder collaboration in housing co-production," International Journal of Housing Policy, vol. 18, no. 1, pp. 55-81, 2018.

[24] X. Gan, J. Zuo, R. Chang, D. Li, and G. Zillante, "Exploring the determinants of migrant workers' housing tenure choice towards public rental housing: a case study in Chongqing, China," Habitat International, vol. 58, pp. 118-126, 2016.

[25] D. O. Mac-Barangod and A. A. Shittu, "Budgetary allocation to the housing sector and the price of some building materials," International Journal of Social Sciences and Management Research, vol. 3, no. 1, pp. 40-53, 2017.

[26] M. Grander, "New public housing: a selective model disguised as universal? Implications of the market adaptation of Swedish public housing," International Journal of Housing Policy, vol. 17, no. 3, pp. 335-352, 2017. 